\title{
Video Evaluation of Table Olive Damage during Harvest with a Canopy Shaker
}

\author{
Sergio Castro-Garcia ${ }^{1}$, Uriel A. Rosa ${ }^{2,7}$, Christopher J. Gliever ${ }^{2}$, \\ David Smith ${ }^{3}$, Jacqueline K. Burns ${ }^{4}$, William H. Krueger ${ }^{5}$, \\ Louise Ferguson ${ }^{6}$, and Kitren Glozer ${ }^{6}$
}

AdDITIONAL INDEX WORDs. fruit impact, Olea europaea, image analysis, bruising, stereo vision

Summary. Table olives (Olea europaea) traditionally are hand harvested when green in color and before physiological maturity is attained. Hand harvesting accounts for the grower's main production costs. Several mechanical harvesting methods have been previously tested. However, tree configuration and fruit injury are major constraints to the adoption of mechanical harvesting. In prior work with a canopy shaker, promising results were attained after critical machine components were reconfigured. In this study, stereo video analysis based on two high-speed cameras operating during the harvesting process were used to identify the sources of fruit damage due to canopy-harvester interaction. Damage was subjectively evaluated after harvest. Fruit mechanically harvested had 35\% more bruising and three times as many fruit with broken skin as that of hand-harvested fruit. The main source of fruit damaged in the canopy was the strike-impact of fruit by harvester rods.

Implementation of softer padding materials were effective in mitigating fruit injury caused by the impact of rods and hard surfaces. Canopy acceleration was correlated with fruit damage, thus restricting improvements needed for fruit removal efficiency through increased tine frequency.

$\mathrm{O}$ lives have been grown in California since the late 1700s. California is the sole commercial source of olives domestically, currently depending on about 1200 growers in the Central Valley (Sacramento and San Joaquin valleys) with biennial production of 115,500 tons (olive is strongly alternate-bearing). The average U.S. table olive production from 2001 to 2006 accounted for only $5.1 \%$ of total world production; the United States is the largest importer of olives at 125,000 tons (International Olive Council, 2007). 'Manzanillo' and 'Sevillano' are the most important domestic cultivars,

The authors wish to acknowledge the support of the California Olive Committee and the cooperation of Bell-Carter Olive Company and Musco Family Olive Company.

${ }^{1}$ Department of Rural Engineering, University of Cordoba, Cordoba, Spain

${ }^{2}$ Biological and Agricultural Engineering Department, University of California, Davis, CA 95616

${ }^{3}$ Dave Smith Engineering, Exeter, CA 93221

${ }^{4}$ Horticultural Sciences Department, University of Florida, Institute of Food and Agricultural Sciences, Citrus Research and Education Center, Lake Alfred, FL 33850

${ }^{5}$ University of California Cooperative Extension, Glenn County, Orland, CA 95963

${ }^{6}$ Department of Plant Sciences, University of California, Davis, CA 95616

${ }^{7}$ Corresponding author. E-mail: uarosa@ucdavis.edu. contributing $76 \%$ and $20 \%$, respectively, of U.S. production (U.S. Department of Agriculture, 2006). Hand harvesting is the main production cost, accounting for $65 \%$ of the gross return per ton in 2005 (Hester, 2006). Unlike other producers outside the United States, California's table olives are primarily processed as "black-ripe canned," with only 5\% processed by other methods. Despite the processed nature of the product, quality of the fresh fruit is the most important factor in developing mechanical harvesting in olives destined for table consumption (Ferguson, 2006).

Mechanical harvesting methods for olives destined for oil have been developed over more than 40 years, focusing on trunk shakers with detached fruit cast over the ground, canvas, or a catch frame. These harvesters maximize harvesting efficiency
(Fridley et al., 1971; Pellenc, 1993); fruit quality is secondary. However, trunk shaker-type harvesters are impractical for table olives due to different tree structures and conditions, as well as the harvest maturity of the fruit (black-ripe for oil olives and green-immature for table olives). Trees are well-irrigated at harvest for table olives; thus, "barking" of the trunks can be problematic (CastroGarcía et al., 2007). Trees producing table olives are often tall, weeping, and old, with fluted, multiple trunks, making trunk attachment difficult or impossible and requiring greater energy input for shaking tall trees (Horvath and Sitkei, 2001). Furthermore, the detachment force required to remove unripe, small olives, averaging 3 to $6 \mathrm{~g}$ each, from pendulous willowy shoots is generally excessive (Kouraba et al., 2004). Fresh green olives are extremely susceptible to mechanical damage. Industrial processing for black table olives can mitigate some damage, but severe bruising, cuts, and abrasions are unacceptable to the consumer.

Some fruit crops, such as citrus (Citrus spp.) or blackberry (Rubus subgenus Rubus) can use canopy harvesters for harvesting processed or fresh market fruit (Peterson, 1998; Takeda and Peterson, 1999). Similar canopy harvesters may prove amenable to table olive harvest. Recent trials with a modified canopy harvester engineered by AgRight (Madera, CA)/Korvan (Lynden, WA) and modified by Dave Smith Engineering (DSE, Exeter, CA) (Fig. 1) removed fruit with $90 \%$ efficiency where fruit was accessible (Ferguson et al., 2006), although fruit damage was still at unacceptable levels. To reduce olive damage, the canopy harvester was modified by the incorporation of padding material to rods and other surfaces likely to contact fruit.

The Korvan/DSE harvester is designed to remove fruit by vibrating

\begin{tabular}{llll}
\hline $\begin{array}{l}\text { Units } \\
\text { To convert U.S. to SI, } \\
\text { multiply by }\end{array}$ & U.S. unit & SI unit & $\begin{array}{l}\text { To convert SI to U.S., } \\
\text { multiply by }\end{array}$ \\
\hline 0.3048 & $\mathrm{ft}$ & $\mathrm{m}$ & 3.2808 \\
4.4482 & $\mathrm{lbf}$ & $\mathrm{N}$ & 0.2248 \\
0.4470 & $\mathrm{mph}$ & $\mathrm{m} \cdot \mathrm{s}^{-1}$ & 2.2369 \\
28.3495 & $\mathrm{oz}$ & $\mathrm{g}$ & 0.0353 \\
0.9072 & ton $(\mathrm{s})$ & $\mathrm{Mg}$ & 1.1023 \\
2.2417 & ton/acre & ${\mathrm{Mg} \cdot \mathrm{ha}^{-1}}^{-1}$ & 0.4461
\end{tabular}




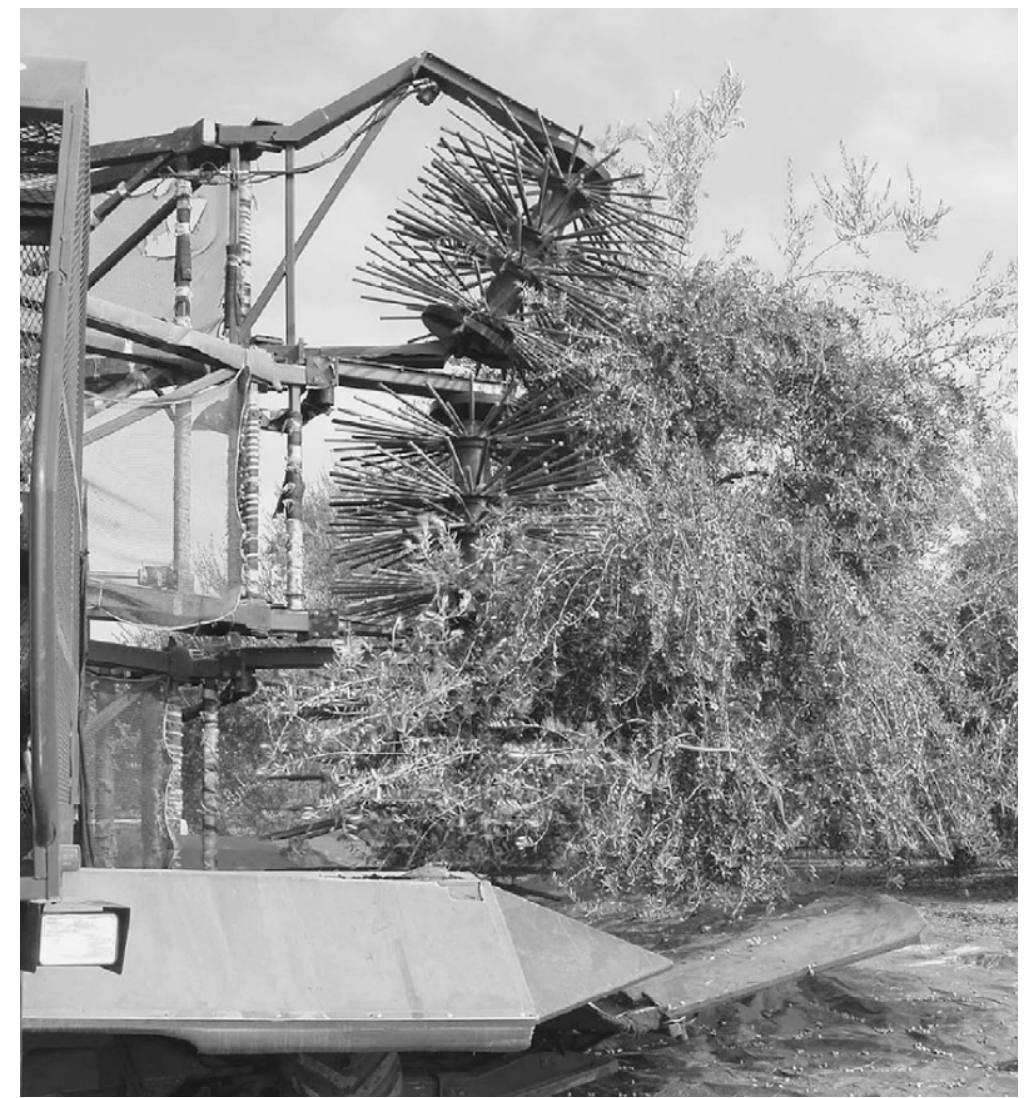

Fig. 1. Experimental olive canopy shaker used during tests on 'Manzanillo' table olives at the University of California Lindcove Experimental Station at Exeter in 2006. The harvester originated as an AgRight (Madera, CA)/Korvan (Lynden, WA)-engineered design prototype and has been modified by Dave Smith Engineering (DSE, Exeter, CA).

the canopy with rods attached radially to the axis of three drums (Fig. 2). Drums are oriented parallel to the tree axis or at $\approx 45^{\circ}$ to the tree axis at the top of the tree. Rods penetrate the canopy on one side of the tree and shake with a predominantly oscillatory movement in the plane of the rods. While this movement is intended to remove fruit with little direct interaction between the rods and fruit, it is inevitable that rods, branches, and olives contact each other, causing mechanical damage to the fruit. Padding material encasing the rods is expected to reduce that damage; however, no documented analysis of the padding quality, or how it might be modified, exists.

Harvester-canopy interaction is a fast and complex process in which a large number of elements are implicated. Thus, high-speed image analysis allows us to study this interaction between short periods of time. Each element position can be calculated by a stereo vision method using two images from different viewpoints based on the triangular measurement principle. This method has been applied in agriculture for estimation of plant geometric attributes (Andersen et al., 2005), location of fruit on trees (Jiménez et al., 2000; Takahashi et al., 2002), and implementation of harvesting robots (Tanigakia et al., 2008; Van Henten et al., 2003).

The main objective of this study was the identification and evaluation of olive damage sources produced in the canopy-harvester interaction to evaluate and recommend alterations to the harvester, while identifying the nature and magnitude of olive fruit damage as a result.

\section{Materials and methods}

Harvest Trial. Olive harvesting tests were carried out in a single day during Oct. 2006 on 'Manzanillo' trees at University of California Riverside's Lindcove Research and Extension Center in Exeter. Trees were planted in 1989 at spacing of $17 \mathrm{ft}$ in-row and $21 \mathrm{ft}$ between rows and with an average height of $14 \mathrm{ft}$. Trees were homogeneous in size and of moderate vigor, producing $\approx 5$ tons/acre when fully cropped. Ten individual trees were machine-harvested for this trial. We used a prototype developed for table olive harvest by AgRight/Korvan and modified by DSE for this work. Because the machine is designed to harvest a single side of the tree at a time and the time required to harvest each side of the tree was longer than the $2.048 \mathrm{~s}$ restriction for recording high-speed video, the tree side was split in two symmetrical quadrants. Each tree was divided into four quadrants determined by the intersection of tree center lines passing on directions parallel and perpendicular to the tree row direction. In all, 21 quadrants were used at random within the 10 trees for harvest evaluation. Six entire trees similarly divided into quadrants were used for hand-harvested comparison, and hand-harvested fruit from these 24-tree quadrants were used as controls, providing a baseline for minimum attainable fruit damage.

Harvesting was carried out with a ground speed of $0.25 \mathrm{mph}$. The two lower drums were oriented parallel to the tree axis and the higher drum was inclined $45^{\circ}$. Two different padding materials were tested for use on the rods: "soft" (with a hardness measurement of 66 Shore A) and "hard" (75 Shore A). The hardness of a material is measured as its surface resistance to penetration of an indenter. The relative hardness of elastic materials such as rubber can be determined on a Shore A scale. Typically, a rubber band (soft) and a shoe heel (hard), give Shore A hardness measurements of 30 and 70, respectively. Both padding materials were installed on different rods in each drum in the tested harvester. Drum frequency was fixed into a small range (180-220 rpm) during field tests according to hydraulic machine regulation. The colors of the soft and hard rod padding materials were black and red, respectively. In video analysis, the materials different colors allowed us to differentiate between soft and hard materials in the captured frames. Two high-speed cameras (FASTCAM-X 1024 PCI camera head; Photron, San Diego, CA) were used to record stereo videos of the canopy shaking 


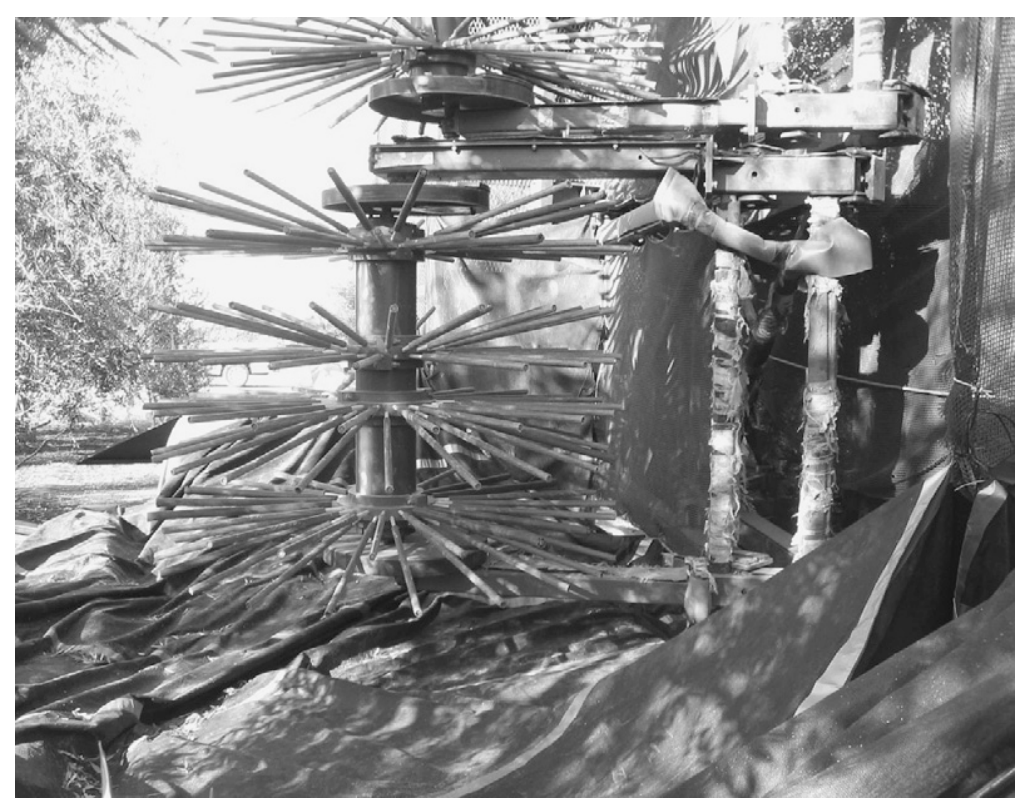

Fig. 2. Vertical drum and horizontal rod radial distribution set-up for the lowest drum of the olive canopy shaker used during experimental tests on 'Manzanillo' table olives at the University of California Lindcove Experimental Station at Exeter in 2006. The harvester originated as an AgRight (Madera, CA)/Korvan (Lynden, WA)-engineered design prototype and has been modified by Dave Smith Engineering (DSE, Exeter, CA).

process to analyze sources of fruit damage. The cameras were attached to a platform mounted on a forklift with 8 -ft separation between cameras. This separation distance was selected according to manufacturer's recommendations to produce the proper view angle from the cameras to the target. Each camera was connected to its own high-speed, solid-state image memory controller. After the camera platform was lifted into a recording position, both cameras were aimed and focused on a customized indexed target (Fig. 3). Subsequently, the recorded grid image was processed in the laboratory to calibrate measurements. ImageExpress MotionPlus tracking software (Sensor Applications, Utica, NY) was used to obtain a three-dimensional solution from two two-dimensional images aimed at the same targeted area on the canopy.

Green Olive DAMAge EVALUATION: COMPARISON BETWEEN MACHINE- AND HAND-HARVESTED FRUIT. Two forms of olive damage were considered in this study: bruising and skin injury (cut or abrasion). Bruising occurs when excessive deformation causes the olive surface to discolor due to oxidation of phenolics. Bruising results from dropping or rough contact by hand or machine, and fruit may be softened without skin rupture. Skin breakage exposes flesh to the environment and fruit quality is irreversibly degraded. Skin injury during hand harvesting is less likely to occur because a relatively sharp edge is normally required to impact the olive for this type of damage.

Machine-harvested olives fell into a soft cloth tarp installed on the harvester catch frame to reduce potential damage by other sources. Fruit were hand collected from the tarp and stored in plastic containers for transportation to the processing facility, where they were visually evaluated before processing. Handharvested trees were sampled by removing fruit by stripping the shoots, the typical commercial harvest method. Fruit from the two harvest methods were compared and damage was evaluated as percentage of fruit harvested with bruises and/or skin injury. The Wilcoxon signed-rank test was used to compare means with JMP statistical software (version 7.0; SAS Institute, Cary, NC).

Video frame analysis: A total OF 15 CAPTURED SEQUENCES WITH NUMEROUS OLIVES WERE PROCESSED FOR THIS ANALYSIS. Each sequence was $2.048 \mathrm{~s}$ in duration and allowed olive counting in the field of view common to both cameras. Olives observed moving in the sequences were either "free" olives falling vertically, therefore probably dropping without deflection by the harvester or branches (and probably not significantly damaged) or olives in relatively horizontal movement, thus probably struck by a rod or branch and potentially significantly injured. Other fruit damage studies consider more parameters to evaluate fruit damage by impacts, but under highly controlled laboratory conditions with respect to how impacts are generated, fruit developmental state, and uniform stage of ripeness (Menesatti and Paglia, 2001). These studies produce predictive models of high accuracy; however, they are not in situ and may introduce experimental error and inaccurate conclusions as a result. In evaluating sources of damage in this study, we assumed that all olives had a similar weight and maturity status. These assumptions in other fruit studies have been made for bruise damage evaluation (Van Zeebroeck et al., 2007). Olive velocity and acceleration values were analyzed as oneway analysis of variance and means ranked with Kruskal-Wallis test at $P \leq$ 0.05 .

Stereo video analysis: Olive TRACKING PROCESS. Recorded videos were displayed at low-speed to identify olive damage sources. When damage events were identified by both cameras, the three-dimensional olive trajectory was determined by a manual tracking process using ImageExpress MotionPlus software. Olive damage was usually caused by an impact; a transient event that involved a short time period. Instantaneous olive velocity and acceleration before and after an impact were considered to evaluate impact magnitude. Velocity and acceleration measurements were computed from three-dimensional position values for a constant frame period of 2 milliseconds. The manual tracking process used on images produced reasonable position accuracy; however, the tracking process generated noise in the data because olives represented a relatively large and homogeneous target, occlusions or shadows occurred in some cases, and low resolution with image magnification. 

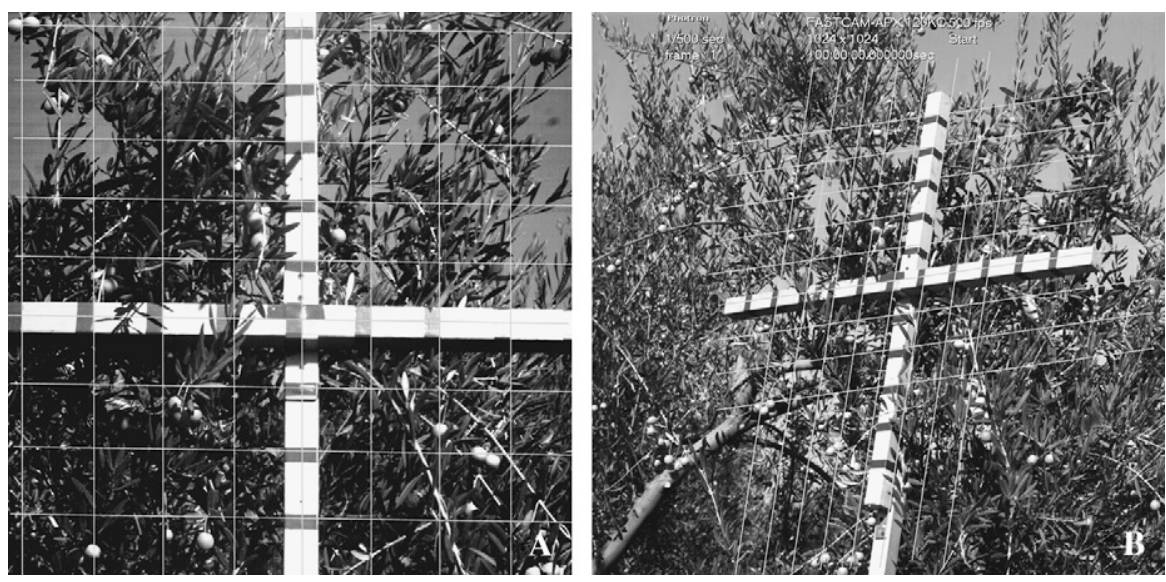

Fig. 3. Stereo high-speed camera images focused on the indexed target and grid used to calibrate frame position measurements of immature green 'Manzanillo' olive fruit and harvester rods of the olive canopy shaker used during experimental tests on 'Manzanillo' table olives at the University of California Lindcove Experimental Station at Exeter in 2006. The picture on the left side (A) was taken with the left video camera, and the picture on the right $(B)$ was taken with the right video camera used to capture images to assess potential for fruit damage during harvest. The harvester originated as an AgRight (Madera, CA)/Korvan (Lynden, WA)engineered design prototype and has been modified by Dave Smith Engineering (DSE, Exeter, CA).

The use of short frame times to calculate velocity values also introduced small errors in calculating accelerations. Thus, it was necessary to verify and calibrate acceleration measurements. Decelerated uniform movement of various objects was analyzed to control the methodology

applied as described above and the quality of obtained data. Of the objects and methods tested for "calibration" purposes, we ultimately decided to use the parabolic trajectory produced when a free falling olive hit a harvester rod. A first point was measured after impact, and a second

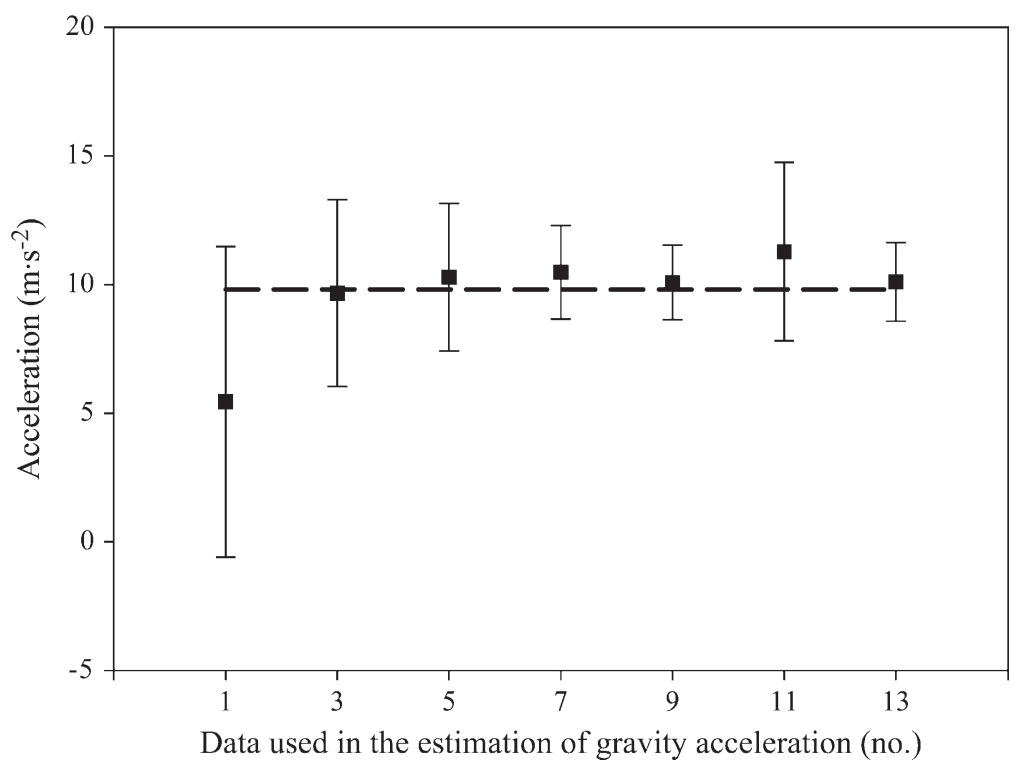

Fig. 4. Estimation of the acceleration of gravity $\left(9.81 \mathrm{~m} \cdot \mathrm{s}^{-2}\right)$ taken with different velocity data sets from immature green 'Manzanillo' olive fruit showing parabolic trajectories produced by free fall olives hit by harvester (experimental olive canopy shaker) rods. Error bars show mean value and SD $(1 \mathrm{~m}=3.2808 \mathrm{ft})$. The harvester originated as an AgRight (Madera, CA)/Korvan (Lynden, WA)-engineered design prototype and has been modified by Dave Smith Engineering (DSE, Exeter, CA). one was taken as the highest vertical height point to define the parabola. Eight olive fruit were tracked on seven different data sets to measure the vertical velocity deceleration (gravity acceleration). Figure 4 shows the results of gravity acceleration estimation. Noise reduction required three or more points to obtain acceleration values close to gravity accelerations and error was reduced by using more points in calculating the average value. Hence, frame time resolution of 2 milliseconds was adequate to identify impacts that occurred between one or two frames and to get a precise fruit trajectory; therefore, impact velocity and acceleration were measured as instantaneous values obtained from the average of three points after impact.

Stereo video anAlysis: Rod HARVESTER-CANOPY INTERACTION. A canopy shaker is designed to remove fruit without direct contact. In this way, a drum transfers energy to the canopy using rods with a periodic movement. Rod movement is the result of canopy-rod interaction, harvester ground speed, drum movement eccentricity, and drum frequency. Harvester ground speed was constant, while drum frequency was modified within a small range (180$220 \mathrm{rpm}$ ) during field tests according to hydraulic machine regulation. Drum eccentricity was a harvesterdesign parameter constant during field tests.

Rod movement through the canopy was studied by position, velocity, and acceleration measurements at the rod tip. In all, nine tracked rod positions in seven different quadrants selected among those used for the trial were tracked to study the harvester setting. For each rod tip cycle into the canopy, four points placed at distances of $\pi / 2$ radians were considered to obtain average values. Canopy vibration was characterized by velocity and acceleration values measured before rods impacted olives. This information was obtained by tracking olives attached to their stems.

\section{Results and discussion}

Percentage of fruit damaged. Fruit sampled from the machine harvest had $35 \%$ more bruising and three times as many fruit with skin injury as that found in hand-harvested fruit (Table 1 ). When video frame analysis 
was used to predict potentially damaged fruit, separated by right and left camera images, no difference in percentage of potential damage was found (Table 2; Student's $t$ test: $\mathrm{t}=$ $2.0518, P>0.05)$. In all, 1226 fruit were evaluated according to their direction of descent. Almost 19\% of removed olives were isolated as potentially highly damaged olives. The percentage of potentially damaged fruit, based on video frame analysis, was considerably less than that actually found in sampled fruit that were counted. This result was anticipated because imagery damage evaluation only estimates olive damage caused by impacts with branches or rods in the focused area, while the sampled fruit likely include damage resulting from all sources in the tree and harvester during the detachment and dropping process.

STEREO VIDEO ANALYSIS: SOURCES OF FRUIT DAMAgE. Of the 21 quadrants chosen for stereo video analysis of machine harvest, 10 quadrants with a total of 42 impacted fruit could be used for damage source analysis. A quadrant was valid to analyze when illumination condition, video reso-

Table 1. Damaged fruit by type of damage as a result of machine or hand harvest of immature green 'Manzanillo' olives; machine harvest by AgRight/Korvan/DSE

harvester. ${ }^{\mathrm{z}}$

\begin{tabular}{llc}
\hline & \multicolumn{2}{c}{ Damaged fruit (\%) } \\
\cline { 2 - 3 } $\begin{array}{l}\text { Harvest } \\
\text { method }^{\mathrm{y}}\end{array}$ & Bruise & $\begin{array}{c}\text { Skin injury } \\
\text { (cut or abrasion) }\end{array}$ \\
\hline Hand & $32.8 \mathrm{a}^{\mathrm{x}}$ & $9.8 \mathrm{a}$ \\
Mechanical & $44.4 \mathrm{~b}$ & $29.8 \mathrm{~b}$ \\
\hline
\end{tabular}

${ }^{2}$ Harvester originated as an AgRight (Madera, CA)/ Korvan (Lynden, WA)-engineered design prototype and has been modified by Dave Smith Engineering (DSE, Exeter, CA).

'Total hand harvest sample equaled 15,688 g (553.4 $\mathrm{oz})$ and mechanical harvest sample equaled $9550 \mathrm{~g}$ $(336.9 \mathrm{oz})$.

${ }^{x}$ Means in the same column with different letters differ by Wilcoxon test at $P<0.05$.

Table 2. Percentage of immature green 'Manzanillo' olives judged as having a high potential for damage as obtained from video frame analysis of the rod harvester-canopy interaction during harvest by AgRight/Korvan/DSE harvester. ${ }^{\mathrm{z}}$ Potential for damage determined by horizontal movement of fruit deflected by harvester rod or branch.

\begin{tabular}{lccc}
\hline & Left camera (\%) & Right camera (\%) & Average (\%) \\
\hline Undamaged olives & 81.7 & 80.4 & 81.1 \\
Potentially damaged olives & 18.4 & 19.6 & 18.9 \\
\hline
\end{tabular}

${ }^{2}$ Harvester originated as an AgRight (Madera, CA)/Korvan (Lynden, WA)-engineered design prototype and has been modified by Dave Smith Engineering (DSE, Exeter, CA).

lution, and the interaction of fruit, canopy, and rod reported a source of fruit damage. Canopy movement produced by rods caused slim fruit-bearing branches to swing at high amplitude (up to $0.2 \mathrm{~m}$ displacement). Olives became detached when a branch experienced a whipping motion or when struck by an object. Two sources of strike-impact were identified: harvester rods striking attached olives in bearing branches (Source 1), and olives attached to different fruit-bearing branches striking each other (Source 2). Impacts with "hard-padded" rods (Source la) were separated from impacts with "soft-padded" rods (Source lb). When other damage sources were branches hitting olives or olives hitting olives, these strikes were seen as barely perceptible impacts and did not significantly affect attachment or trajectory of fruit struck in these manners. Olives detached solely by canopy vibration dropped vertically; some of these were observed hitting hard-padded rods, thus becoming significantly damaged (Source 3 ). Fruit that dropped vertically and hit branches or other still-attached olives when detached by canopy vibration were not detected or exhibited insignificant damage and thus were not detectable. Source 1 damage occurred to 26 fruit, 17 of which were impacted with hardpadded rods (Source la) and 9 fruit with soft-padded rods (Source lb). Seven olives displayed "Source 2" damage; nine fruit had "Source 3" damage. Thus, the majority of severe damage was inflicted by rods.

Table 3 presents olive velocity and acceleration values before and after impacts. Results showed high variability due to the particular condition of each impact: different impact time, angle, and rod velocity (lowest close to drum and maximum at the rod tip). About $60 \%$ of samples had reduced velocity after impact with rods or other olives. Impacts between olive and canopy or rod coinciding in the same movement direction were less severe. Still-attached olives showed acceleration before impact close to $600 \mathrm{~m} \cdot \mathrm{s}^{-2}$. Sources la and 3 were the most important potential damage sources, without significant differences between them. All impacts of these kinds were with hard material padding. Source $1 \mathrm{~b}$ (fruit impacts with soft-padded material) showed lower impacts than impacts with hard-padded material. Olives shaken free and sustaining damage by impacting hard-padded rods (Source 3 ) also appeared to contribute to the incidence of olives thrown across the catch frame; this damage source should be reduced to improve harvest efficiency. Possibilities for harvester modification to reduce Source 3 damage include: reducing the number of rods, selecting soft rod padding materials, and deflecting or interfering with upper canopy detached olives hitting the bottom drum rods.

Analysis of the sources of damage and their relative incidence led to preliminary considerations for harvester modification. Results from Sources la- and 3 -induced damage indicated advantages to using rods with soft padding materials, with larger material deformation, more impact energy absorbed, and longer impact time. We did not evaluate whether harvest efficiency (ability to remove fruit) was significantly different between rods padded with hard or soft materials. Acceleration values produced by olive impacts considered for Source 2, before and after impact, did not show significant differences and had the lowest acceleration value among considered sources. Accordingly, Source 2 damage was given the lowest priority and we concluded that harvester modifications to address this damage were unwarranted.

STEReO Video anAlysis: RoD HARVESTER-CANOPY INTERACTION. Rod movement is responsible for transmitting energy to the canopy to cause fruit detachment, but it is also the main source of fruit damage. By analysis of tracked data, we concluded that rod trajectory could be reduced to a periodic movement. Rod trajectory into the canopy showed that rod amplitude movement in the horizontal plane was a predominant movement component and was kept similar along tests. The rod horizontal 
Table 3. Mean velocity and acceleration of immature green 'Manzanillo' olives before and after impacts as identified damage sources during harvest by AgRight/Korvan/DSE harvester. ${ }^{\mathrm{z}}$ Sources of damage were rods of the harvester with different padding or attached fruit impacting each other.

\begin{tabular}{llcc}
\hline $\begin{array}{l}\text { Source of olive } \\
\text { impact damage }\end{array}$ & Impact & $\begin{array}{c}\text { Velocity } \\
{\left[\mathbf{m} \cdot \mathbf{s}^{-1}(\mathrm{sD})\right]^{\mathrm{y}}}\end{array}$ & $\begin{array}{c}\text { Acceleration } \\
{\left[\mathbf{m} \cdot \mathrm{s}^{-2}(\mathrm{sD})\right]^{\mathrm{y}}}\end{array}$ \\
\hline Source la: Hard-padded rods & Before & $1.9(1.2) \mathrm{a}^{\mathrm{x}}$ & $648(362) \mathrm{a}$ \\
& After & $2.5(0.6) \mathrm{b}$ & $855(327) \mathrm{b}$ \\
Source 1b: Soft-padded rods & Before & $2.4(1.0) \mathrm{b}$ & $691(303) \mathrm{b}$ \\
& After & $2.6(0.8) \mathrm{b}$ & $587(317) \mathrm{a}$ \\
Source 2: Olives on & Before & $1.8(1.0) \mathrm{a}$ & $587(281) \mathrm{a}$ \\
different branches & & & \\
striking each other & After & $1.7(0.6) \mathrm{a}$ & $441(196) \mathrm{a}$ \\
& & & \\
Source 3: Vertical drop, & Before & $2.9(1.0) \mathrm{b}$ & $599(328) \mathrm{a}$ \\
hitting hard-padded rods & After & $2.1(0.8) \mathrm{a}$ & $866(263) \mathrm{b}$
\end{tabular}

${ }^{2}$ Harvester originated as an AgRight (Madera, CA)/Korvan (Lynden, WA)-engineered design prototype and has been modified by Dave Smith Engineering (DSE, Exeter, CA).

${ }^{\mathrm{y}} 1 \mathrm{~m}=3.2808 \mathrm{ft}$.

${ }^{x}$ Means in the same column with different letters differ by Kruskal-Wallis test at $P<0.05$.

Table 4. Comparison of velocity and acceleration between harvester rods and immature green 'Manzanillo' olives before detachment from the canopy as a measure of vibration transference obtained by stereo vision analysis of video recorded during harvest by AgRight/Korvan/DSE harvester. ${ }^{\mathrm{z}}$

\begin{tabular}{llcc}
\hline & & Harvester rods & Attached olives \\
\hline Velocity & $\mathrm{m} \cdot \mathrm{s}^{-1}(\mathrm{sD})^{\mathrm{y}}$ & $2.4(0.4)$ & $2.0(0.9)$ \\
Acceleration & $\mathrm{m} \cdot \mathrm{s}^{-2}(\mathrm{sD})^{\mathrm{y}}$ & $563(279)$ & $647(324)$ \\
\hline
\end{tabular}

${ }^{2}$ Harvester originated as an AgRight (Madera, CA)/Korvan (Lynden, WA)-engineered design prototype and has been modified by Dave Smith Engineering (DSE, Exeter, CA).

${ }^{\mathrm{y}} \mathrm{l} \mathrm{m}=3.2808 \mathrm{ft}$.

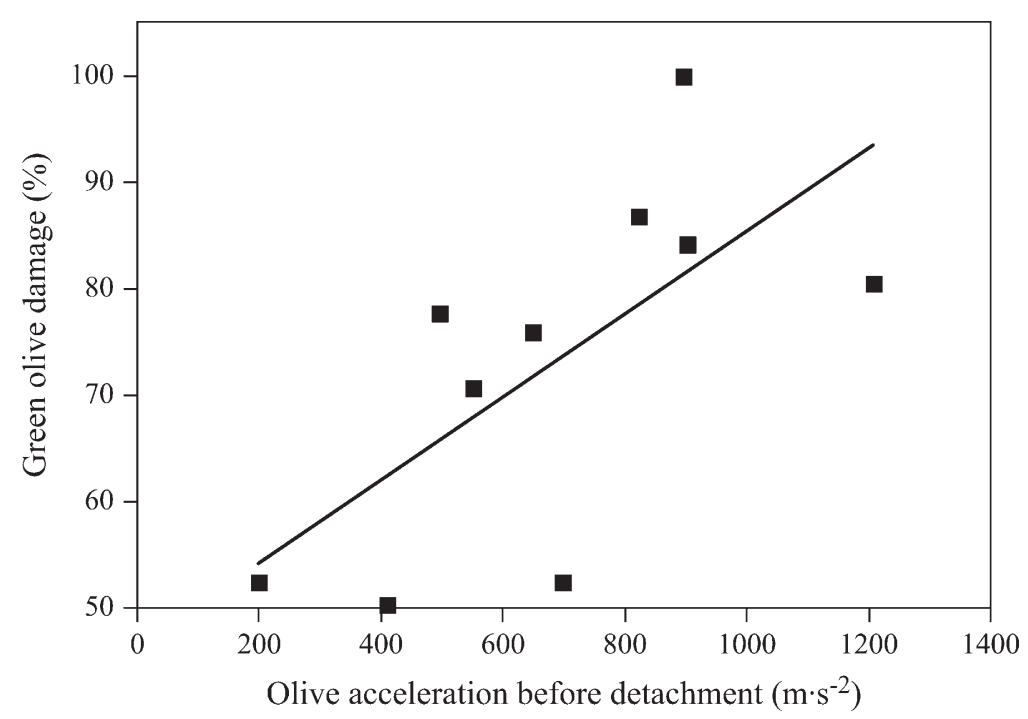

Fig. 5. Measured acceleration of immature green 'Manzanillo' olive fruit before detachment from the canopy with stereo video cameras and computer software versus actual green olive damage induced by the experimental olive canopy shaker. The harvester originated as an AgRight (Madera, CA)/Korvan (Lynden, WA)engineered design prototype and has been modified by Dave Smith Engineering (DSE, Exeter, CA); $1 \mathrm{~m}=3.2808 \mathrm{ft}$. amplitude into the canopy was 0.149 $m$ with a frequency of $5.26 \mathrm{~Hz}(315.6$ rod cycles into the canopy per minute). Rod movement at the tip featured a mean tangential velocity of $2.4 \mathrm{~m} \cdot \mathrm{s}^{-1}$ and mean acceleration value of $563 \mathrm{~m} \cdot \mathrm{s}^{-2}$.

Table 4 presents similar velocity and acceleration values for rods and attached olives in the canopy. Stereo low-speed video inspection allowed us to observe that olives in the branches followed the rod periodic movement with similar frequency but longer amplitudes. Canopy shaking was similar to rod movement: velocity values close to $2 \mathrm{~m} \cdot \mathrm{s}^{-1}$ and instantaneous acceleration close to $600 \mathrm{~m} \cdot \mathrm{s}^{-2}$. This approximates a fruit removal force of 3 $\mathrm{N}$ for a 5-g olive fruit. Previous studies with 'Manzanillo' table olives measured the mean fruit removal force from 4 to $5 \mathrm{~N}$ in California growing locations (Burns et al., 2008; Denney and Martin, 1994). The high force calculated in each case illustrates the difficulty in removing olive fruit with the canopy shaker. While abscission agent application could reduce the force required to remove immature olives, decades of research on table olives under California conditions have not resulted in an acceptable commercial practice. Other research has reported better success with abscission agent application and/or mechanical harvest methods; Sessiz and Özcan (2006) increased harvest efficiency from less than $50 \%$ to close $96 \%$ using abscission treatments and a branch shaker.

MECHANICAL HARVESTING OLIVE DAMAge EVAlUation. Data on acceleration of 33 olives (Sources 1 and 2) obtained from 10 quadrants were compared with the corresponding percentage of green olive damage (Fig. 5 ). A positive linear correlation between green olive damage and olive acceleration measured in the canopy from fruit before impact (Pearson correlation $=0.674$ ) was found, indicating higher olive damage with increasing canopy acceleration. However, the linear fit showed a low coefficient of determination $\left(r^{2}=0.455\right)$ as a result of previously stated assumptions and difficult-to-control field conditions. Considering only canopy acceleration was insufficient to obtain a high prediction value of green olive damage. Using these analyses, we established a damage-acceleration threshold to 
isolate and prevent high olive damage for the harvester's current configuration. Olive acceleration levels up to $800 \mathrm{~m} \cdot \mathrm{s}^{-2}$ generated more than $80 \%$ damaged olives. Thus, changing machine configuration by increasing drum frequency to obtain higher olive acceleration is limited by green olive damage.

Other alternatives such as drum inclination, rod length, drum vertical separations (to avoid re-entry of detached olives into another drum), and abscission treatments must be evaluated to improve machine-harvested olive quality and increase harvest efficiency. Additional considerations important to reduce fruit damage include clarifying the relationship between drum frequency and rod density with canopy acceleration and evaluation of different ground speeds. In addition to setting an acceptable damage threshold for green olives, it will be necessary to optimize the harvester for high removal efficiency and low olive damage.

\section{Literature cited}

Andersen, H.J., L. Reng, and K. Kirk. 2005. Geometric plant properties by relaxed stereo vision using simulated annealing. Comput. Electron. Agr. 49:219-232.

Burns, J.K., L. Ferguson, K. Glozer, W.H. Krueger, and R.C. Rosecrance. 2008. Screening fruit loosening agents for black ripe processed table olives. HortScience 43:1449-1453.

Castro-García, S., J.A. Gil-Ribes, G.L. Blanco-Roldán, and J. Agüera-Vega. 2007. Mode shapes evaluation of trunk shakers used in oil olive harvesting. Trans. Amer. Soc. Agr. Biol. Eng. 50:727-732.
Denney, J.O. and G.C. Martin. 1994. Ethephon tissue penetration and harvest effectiveness in olive as a function of solution $\mathrm{pH}$, application time, and BA or NAA addition. J. Amer. Soc. Hort. Sci. 119:1185-1192.

Ferguson, L. 2006. Trends in olive fruit handling previous to its industrial transformation. Grasas Aceites 57(1):9-15.

Ferguson, L., J.K. Burns, K. Glozer, C. Crisosto, V. Bremer, W.H. Krueger, and R. Rosecrance. 2006. Mechanical harvester efficiency and damage evaluations. 6 Jan. 2008. <http://groups.ucanr.org/ olive_harvest/Research_Proposals_\&_ Reports/Reports_for_2006.htm>.

Fridley, Y., J. Hartman, P. Chen, and P. Whisler. 1971. Olive harvest mechanization in California. California Agr. Expt. Sta. Bul. 885 .

Hester, A. 2006. Olive growers "wrap up" and begin plans for 2006. Olive Grower Council Nwsl., Visalia, CA.

Horvath, E. and G. Sitkei. 2001. Energy consumption of selected tree shakers under different operational conditions. J. Agr. Eng. Res. 80:191-199.

International Olive Council. 2007. World table olive figures. 14 Sept. 2007. <http://www.internationaloliveoil.org/ web/aa-ingles/corp/AreasActivitie/ economics/AreasActivitie.html>.

Kouraba, K., J.A. Gil-Ribes, G.L. BlancoRoldán, M.A. De-Jaime, and D. Barranco. 2004. Suitability of olive varieties for mechanical shake harvesting. Olivae 101:38-43.

Jiménez, A.R., R. Ceres, and J.L. Pons. 2000. A survey of computer vision methods for locating fruit on trees. Trans. Amer. Soc. Agr. Biol. Eng. 43:19111920.

Menesatti, P. and G. Paglia. 2001. Development of a drop damage index of fruit resistance to damage. J. Agr. Eng. Res. 80:53-54.

Pellenc, R. 1993. Mechanical harvesting of olives with shaker frequency and amplitude control. Proc. Fruit Nut Veg. Production Eng. 4:327-330.

Peterson, D.L. 1998. Mechanical harvester for process oranges. Appl. Eng. Agr. 14:455-458.

Sessiz, A. and M.T. Özcan. 2006. Olive removal with pneumatic branch shaker and abscission chemical. J. Food Eng. 76:148-153.

Takahashi, T., S. Zhang, and H. Fukuchi. 2002. Measurement of 3-D locations of fruit by binocular stereo vision for apple harvesting in an orchard. Proc. Amer. Soc. Agr. Biol. Eng. Ann. Intl. Mtg. Paper No. 021102 .

Takeda, F. and D.L. Peterson. 1999. Consideration for machine harvesting fresh-market eastern thorn less blackberries: Trellis design, cane training system and mechanical harvesting developments. HortTechnology 9:16-21.

Tanigakia, K., T. Fujiuraa, A. Akaseb, and J. Imagawac. 2008. Cherry-harvesting robot. Comput. Electron. Agr. 63:65-72.

U.S. Department of Agriculture. 2006. California olive probability survey report. 17 Sept. 2007. <http://www.nass.usda.gov/ Statistics_by_State/California/Publications/ Fruits_and_Nuts/indexfor.asp>.

Van Henten, E.J., B.A.J. Van Tuijl, J. Hemming, J.G. Kornet, J. Bontsema, and E.A. Van Os. 2003. Field test of an autonomous cucumber picking robot. Biosystems Eng. 86:305-313.

Van Zeebroeck, M., V. Van Linden, P. Darius, B. De Ketelaere, H. Ramon, and E. Tijskens. 2007. The effect of fruit factor on the bruise susceptibility of apples. Postharvest Biol. Technol. 46:10-19. 